\title{
Changing Wildlife Populations in Nairobi National Park and Adjoining Athi-Kaputiei Plains: Collapse of the Migratory Wildebeest
}

\author{
Joseph O. Ogutu ${ }^{1,3, *}$, Norman Owen-Smith ${ }^{2}$, Hans-Peter Piepho ${ }^{1}$, Mohammed Y. Said ${ }^{3}$, Shem C. \\ Kifugo $^{3}$, Robin S. Reid ${ }^{4}$, Helen Gichohi ${ }^{5}$, Paula Kahumbu ${ }^{6}$ and Samule Andanje ${ }^{7}$ \\ ${ }^{1}$ University of Hohenheim, Institute for Crop Science-340, 70599 Stuttgart, Germany \\ ${ }^{2}$ School of Animal, Plant and Environmental Sciences, University of the Witwatersrand, Wits 2050, South Africa \\ ${ }^{3}$ International Livestock Research Institute, P.O. Box 30709-00100, Nairobi, Kenya \\ ${ }^{4}$ Natural Resource Ecology Laboratory and Dept of Ecosystem Science and Sustainability, Colorado State University, \\ Fort Collins, C), 80524, USA \\ ${ }^{5}$ African Wildlife Foundation. Ngong Road, Karen. Box 310, 00502, Nairobi, Kenya \\ ${ }^{6}$ WildlifeDirect. Africa Conservation Fund (KENYA), Nairobi, Kenya \\ ${ }^{7}$ Kenya Wildlife Service, P. O. Box 40241, Nairobi, Kenya
}

\begin{abstract}
There is mounting concern about declines in wildlife populations in many protected areas in Africa. Migratory ungulates are especially vulnerable to impacts of changing land use outside protected areas on their abundance. Range compression may compromise the capacity of migrants to cope with climatic variation, and accentuate both competitive interactions and predation. We analyzed the population dynamics of 11 ungulate species within Kenya's Nairobi National Park, and compared them to those in the adjoining Athi-Kaputiei Plains, where human settlements and other developments had expanded. The migratory wildebeest decreased from almost 30,000 animals in 1978 to around 5,000 currently but the migratory zebra changed little regionally. Hartebeest, impala, eland, Thomson's gazelle, Grant's gazelle, waterbuck, warthog and giraffe numbers declined regionally, whereas buffalo numbers expanded. Bimonthly counts indicated temporary movements of several species beyond the unfenced park boundaries, especially during very wet years and that few wildebeest entered the park during the dry season following exceptionally wet conditions in 1998. Wildebeest were especially vulnerable to anthropogenic impacts in their wet season dispersal range on the plains. Deterioration in grassland conditions in the park following high rainfall plus lack of burning may have discouraged these animals from using the park as a dry season refuge. Our findings emphasise the interdependency between the park and the plains for seasonal wildlife movements, especially in exceptionally dry or wet years. To effectively conserve these ungulates, we recommend implementation of the new land-use plan for the Athi-Kaputiei Plains by the county government; expansion of the land leasing program for biodiversity payments; collecting poacher's snares; negotiation and enforcement of easements, allowing both wildlife and livestock to move through the Athi-Kaputiei Plains, providing incentives for conservation to landowners; and improving grassland conditions within the park through controlled burning so that more wildlife can gain protection there.
\end{abstract}

Keywords: Population dynamics, animal movements, migration, land use transformation, global warming, rainfall influences, NDVI, protected area management.

\section{INTRODUCTION}

There is growing concern that the protected areas established to conserve Africa's wildlife resources are inadequate to perform this function and that wider measures are needed to sustain the regional diversity of large mammals $[1,2]$. The fundamental problem is that most national parks and game

*Address correspondence to this author at the University of Hohenheim, Institute for Crop Science-340, 70593 Stuttgart, Germany;

Tel: +49-711-459 23022; Fax: +49-711-459-24345;

E-mail: jogutu2007@gmail.com reserves are too small to encompass the full extent of the movements formerly undertaken by these large herbivores to cope with environmental variation both within and between years. In addition, while African parks were established on the lands of local peoples by governments [3], most local peoples benefit little from wildlife [4] and thus have little incentive to help conserve migrants when they move out of parks. Thus, human settlements and associated activities in the adjoining land are often expanding without consideration of the need for open land to accommodate migratory wildlife, which then exacerbates the range restrictions [5], and adds to the isolation of protected areas [6]. A further major 
threat is global warming [7], and the greater frequency and intensity of droughts and floods that are expected to result [8]. Inappropriate management responses may worsen the capacity of these areas to protect their full legacy of large mammals [9].

Populations of species that migrate widely are especially at risk [10]. Wildebeest Connochaetes taurinus (Burchell) populations have collapsed to a small fraction of their former abundance following obstruction of their movements in the central Kalahari region of Botswana [11], Etosha Pan in Namibia [12], Mara-Loita Plains in Kenya [13], and TarangireSimanjiro region of Tanzania [14]. Other commonly migratory or wide ranging species that are vulnerable to range compression or truncation include plains zebra Equus burchelli (Gray) [15], Thomson's gazelle Eudorcas thomsoni (Brooke) [16], and eland Taurotragus oryx (Pallas) [17]. Population fluctuations as well as wider movements of large herbivores in African savanna ecosystems are largely a response to rainfall variation, determining seasonal vegetation growth [18] as well as retention of green leaves through the dry season [19]. In both eastern and southern Africa, interannual variation in rainfall is affected by the El NiñoSouthern Oscillation (ENSO), leading to quasi-cyclic variation in habitat conditions $[20,21]$. While most large herbivore populations respond positively to the increased grass production promoted by higher rainfall, there are notable exceptions. The taller grass resulting from higher rainfall may increase cover for stalking predators, making their favoured prey species more vulnerable to predation [22, 23]. Excessive rainfall can be detrimental through waterlogging of soils and by promoting taller, more fibrous grasses [24]. Rain falling during the normally dry season months may have a greater influence on ungulates than the wet season amount [25]. However, the interplay of rainfall variability and land use change on ungulate population dynamics has thus far attracted relatively little attention.

Nairobi National Park (Park) is situated at the northern extent of the Athi-Kaputiei Plains (Plains) ecosystem in Kenya [26]. The park's future as a wildlife reserve and tourist attraction close to the city of Nairobi is in jeopardy because of heavy poaching, construction of roads, industrial expansion, growing towns, and expansion of fencing on the plains to the south, which serve as the dispersal range for wildlife populations [26-29]. Small efforts are underway here to give local residents incentives to leave land open for wildlife, but the scale would have to be expanded tremendously to cover the full extent of the dispersal areas required by the migratory ungulates.

Our prime aim in this paper is to evaluate potential causes of the recent substantial collapse in the numbers of wildebeest population migrating between Nairobi National Park and the adjoining Athi-Kaputiei Plains [26, 30], in comparison with the population changes and movements shown by other ungulate species. Our particular concern is to separate out the effects of changing rainfall and associated habitat conditions from consequences of the land use developments to the south of the park. We draw on information provided by sporadic counts of ungulate populations extending over almost five decades, focussing especially on the total-area counts of all larger ungulates carried out bimonthly within the park between 1990 and 2011. Our assessment extends earlier reports that did not consider seasonal varia- tions or the effects of annually variable rainfall [26, 31-36]. We expected to find that (1) substantial population declines would be associated with extreme wet or dry years, (2) migratory species would show the greatest population decline, and (3) non-migratory species would decrease more in the Athi-Kaputiei Plains to the south than within the national park.

\section{METHODS}

\section{Study Area}

Nairobi National Park encompasses $117 \mathrm{~km}^{2}$ at an altitude of 1600-1800 m between latitudes $1^{\circ} 20^{\prime}-1^{\circ} 26^{\prime} \mathrm{S}$ and longitudes $36^{\circ} 50^{\prime}-36^{\circ} 58^{\prime} \mathrm{E}$. The park was established on the borderlands between pastoral grazing lands and highland farming areas in 1946. It is separated from Nairobi Metropolis in the north by a wire fence, and its eastern and western boundaries are also fenced. Its open southern boundary is formed by the Empakasi River. The Kitengela region immediately to the south was part of the Kitengela Conservation Area $\left(777 \mathrm{~km}^{2}\right)$, which, in turn, was part of the Ngong National Reserve $\left(1178.44 \mathrm{~km}^{2}\right)$ that formerly adjoined the Nairobi National Park and was officially gazetted in September 1949 [37, p. 311]. Though not officially degazetted as a game conservation area this Reserve has since become settled by Maasai pastoralists and their livestock and immigrant populations [30, 38].

The Athi-Kaputiei Plains (Plains), as defined by the movements of migratory ungulates, covers a total area of about $2200 \mathrm{~km}^{2}$. Its limits are bounded by the Rift Valley escarpment to the west, the Nairobi-Mombasa railway in the east, and the Konza-Magadi railway in the south (Fig. A1 in Supplementary material A). Rainfall decreases from over $800 \mathrm{~mm}$ in northern Nairobi Park to under $500 \mathrm{~mm}$ in the extreme south-east of the Plains.

Vegetation within Nairobi Park consists mostly of open grasslands with scattered low Acacia drepanolobium trees, plus wooded river margins and a forest on elevated terrain in the west. Soils are predominantly grey or reddish clays prone to water logging. The most common grass species are Pennisetum mezianum, Bothriochloa insculpta, Themeda triandra and Digitaria macroblephora [32]. Somali pastoralists living within Nairobi Park were evicted in May 1967 to reduce competition between livestock and wildlife [31]. Controlled burning was discontinued after the mid-1970s [39], although accidental fires occasionally extend into the park. Fifteen dams augment pools in rivers in supplying drinking water for wildlife. Human settlements and livestock, plus associated cultivated fields, roads, fences, mines, quarries, dams and some major industries now occur densely in the AthiKaputiei ecosystem (Fig. A1).

\section{ANNUAL CLIMATE AND VEGETATION VARIA- TION}

\section{Rainfall and Air Temperature}

Rainfall has been recorded at four locations around the edge of Nairobi Park: Cheetah Gate in the south-east (197697), Wardens' Camp in the west (1976-92), Wilson Airport to the north-west (1957-2013) and Jomo Kenyatta Airport to the north-east (1958-2013). Mean annual rainfall (October- 


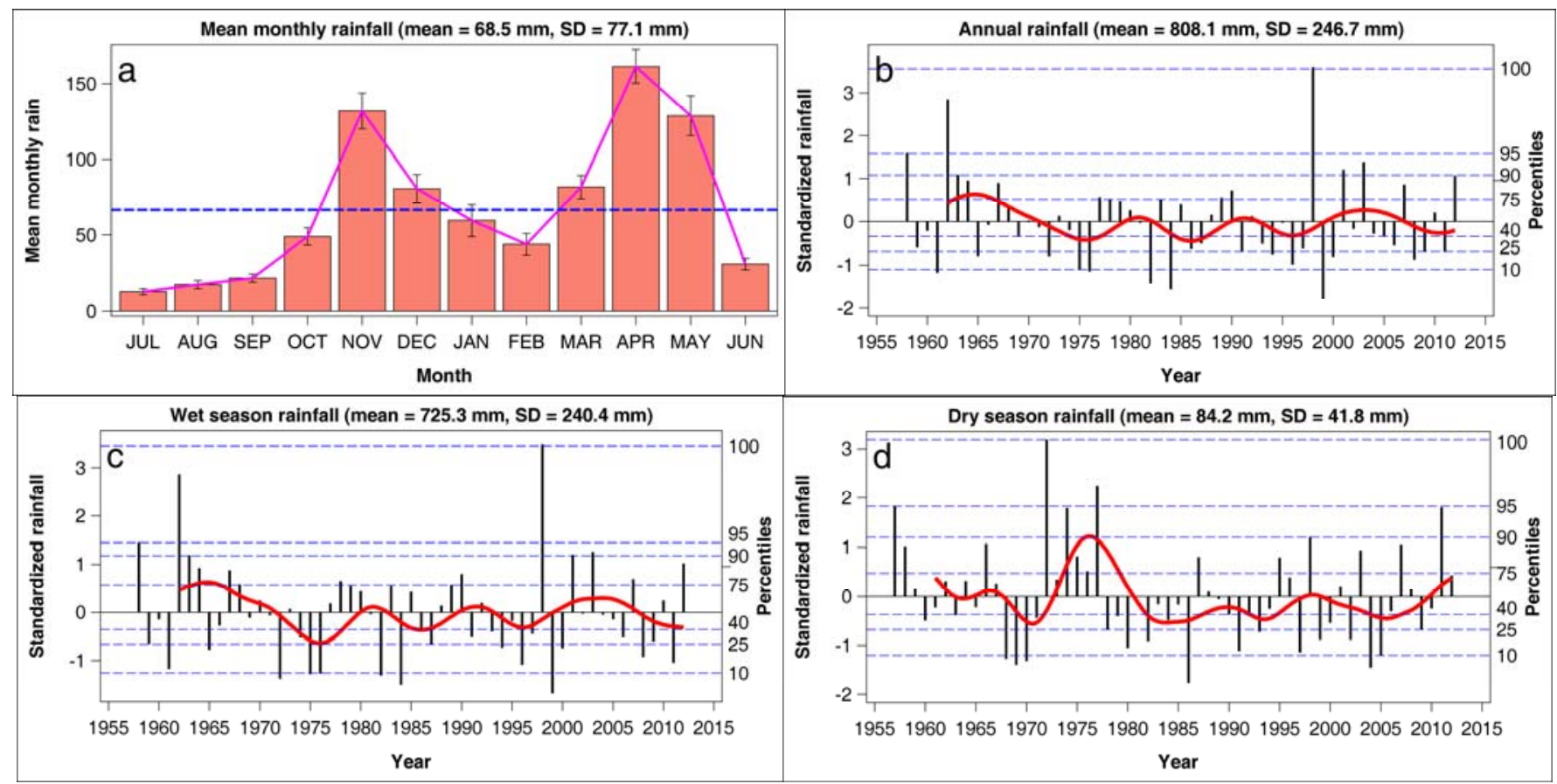

Fig. (1). Trends in mean monthly rainfall in mm and in standardized wet (October-May) and dry (June-September) season and annual (October-September) rainfall in and around Nairobi National Park during January 1957-April 2013. Dashed horizontal lines are the 10, 25, 40, 50, $75,90,95$ and $100^{\text {th }}$ percentiles of the frequency distribution of rainfall normalized to zero mean and unit variance. Solid lines are the 5-year moving averages of rainfall components. Needles are the normalized rainfall values.

September) varied from $912 \mathrm{~mm}$ (range 441-1799 $\mathrm{mm}$ ) at Wilson airport to $524 \mathrm{~mm}$ (range $377-825 \mathrm{~mm}$ ) at Cheetah Gate (Fig. A1 in Supplementary material A). For analysis, we averaged the rainfall records over all stations (annual mean $=808 \pm 247 \mathrm{~mm}$, range 366-1697 mm; Supplementary Material D). Monthly rainfall shows a major peak in April during the long rains spanning March-May, and a minor peak in November during the short rains extending through November-December (Fig. 1a). The rainfall measures we used were the October-September annual totals, OctoberMay wet season amounts, June-September dry season amounts, and early (October-January) and late (FebruaryMay) wet season components. We considered also the effects of prior rainfall potentially influencing habitat conditions, averaged over moving windows of 4 to 6 years prior to the census to correspond with phases of the rainfall oscillation evident in the region [21]. Temperature records for 19602013 were obtained from Wilson Airport.

Annual vegetation production and greenness retention were assessed using the Advanced Very High Resolution Radiometer Normalized Difference Vegetation Index (NDVI) data from NOAA covering Nairobi Park downloaded for 1982-2009 at a spatial resolution of $8 \mathrm{~km} \times 8 \mathrm{~km}$ from the website of FEWS Net (http://earlywarning.usgs.gov/fews/africa/web/datatheme.php?imgtype $=$ n7\& extent $=\mathrm{a}$ \&begdek $=1$ \&enddek $=36$ \&begyear $=$ \&endyear $=\&$ cachekiller $=1096.4434700856252)$. We computed monthly averages and standardized them to zero mean and unit variance for the seasonal blocks defined above.

\section{ANIMAL COUNTS}

Monthly counts of animals within Nairobi Park were carried out by Kenya Wildlife Service (KWS) staff and vol- unteers from vehicles from July 1960 through 1981 except in 1964-65, 1978 and 1980. Bimonthly ground counts were resumed in November 1989 and conducted regularly in most years thereafter (Supplementary Materials $\mathbf{D}$ and $\mathbf{E}$ ). The same counting protocol has been used since counts begun. The park was subdivided into 15 counting blocks based on roads, rivers, ridges and other landscape features (Fig. A2), each of which was covered between 06:00 and 10:00 hrs recording all of the common ungulate species.

A 4-wheel-drive vehicle was used per block except when the presence of large migratory herds, or heavy rains reduced accessibility and necessitated the use of additional vehicles in a block. Each counting team of volunteers had a driver and at least one recorder and observer, drawn from Friends of Nairobi National Park, KWS rangers and researchers, wildlife clubs of Kenya, Nature Kenya, students or other interested individuals. Volunteers are encouraged to count in the same block for consistency and some had counted regularly in one block for more than a decade. Each counting team had an experienced counter (team leader), who trained new counters before they could be assigned to a block on their own. The same tracks were followed and the same distances covered for consistency, except when bad weather conditions made detours unavoidable. Counting vehicles followed fixed tracks to minimize damage to vegetation and vehicles but sometimes drove off-track to get better counts except in blocks (e.g. 14 and 15) covered by thick forests where off-track detours are difficult. Animals were spotted and counted with the aid of binoculars. Vehicles were stopped periodically at vantage points to scan the surroundings for animals, sometimes from the rooftops of the vehicles. Counters from adjacent blocks cross-checked their data during and at the end of each count to ensure that animals that occurred near the boundaries or moved between blocks 


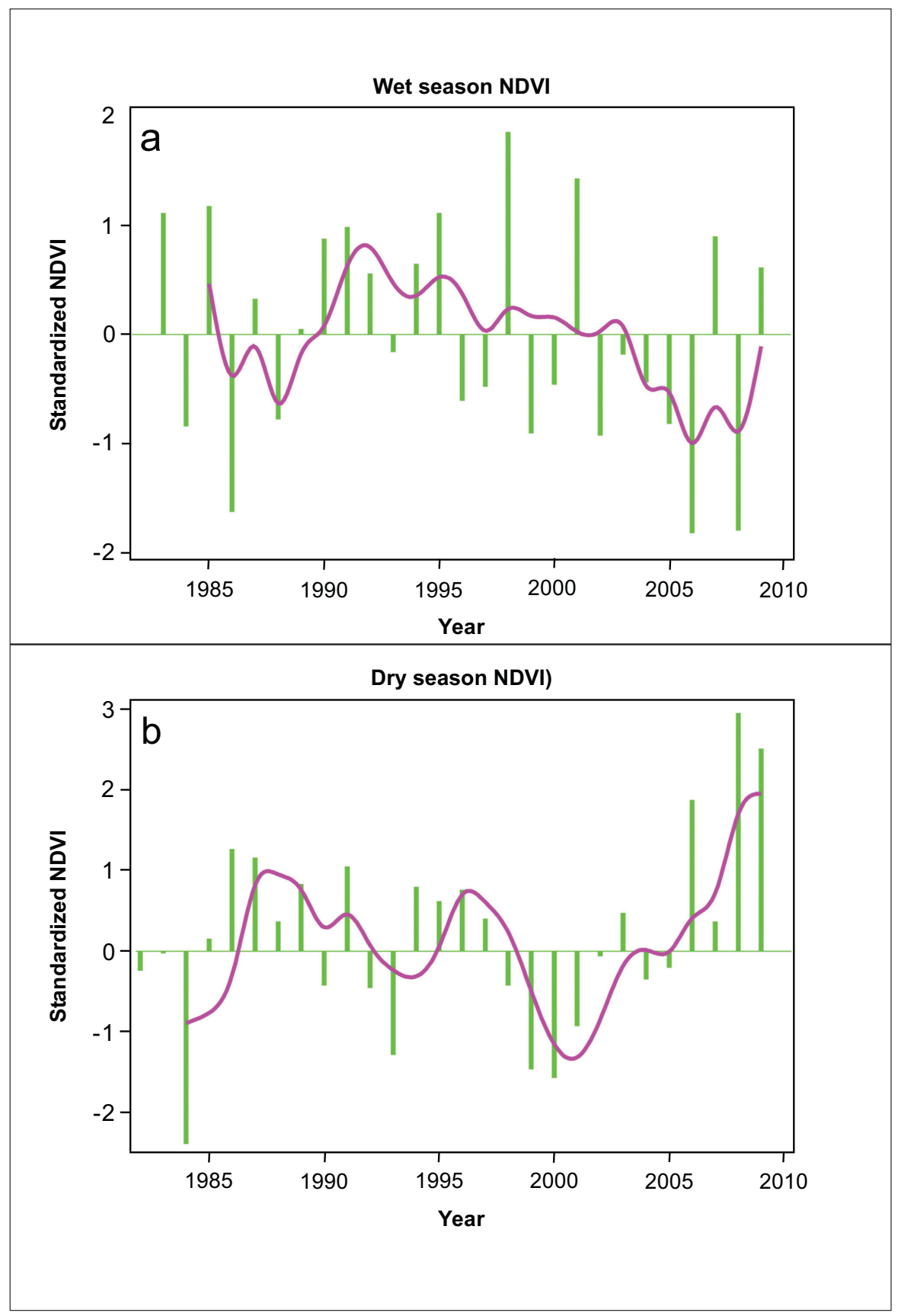

Fig. (2). Trends in standardized dry and wet season Normalized Difference Vegetation Index components in Nairobi National Park during January 1982 to October 2009.

during counts were not missed, or double-counted. Nevertheless, individuals of species that seasonally wander beyond the park boundaries may be missed and their numbers may vary between counts as a result. Since the coverage of the park was consistent and comprehensive, any sighting and observer biases in the ground censuses, if any, were probably minor.

Aerial sample counts $(n=24)$ of wildlife and livestock were conducted irregularly in the Athi-Kaputiei Ecosystem (excluding Nairobi Park) from 1977 to 2011 by the Department of Resource Surveys and Remote Sensing (DRSRS) of Kenya using systematic aerial reconnaissance flights [36, 38, 40] as part of an ongoing Kenya-wide rangeland monitoring program (Supplementary Materials C). Transects oriented in an east-west direction were flown at $5-\mathrm{km}$ intervals at a nominal height of $91 \mathrm{~m}$ above ground. Two observers occupying the rear section of a light aircraft counted animals located between two rods attached to the wing struts. The field of vision between these rods projected a census strip that was calibrated by flying repeatedly across ground markers of known spacing. The survey strip (total of both sides of the aircraft $=294.6 \pm 54.1 \mathrm{~m})$ was calculated and used to determine the sampling intensity $(6.01 \pm 1.70 \%)$. The numbers of animals within survey strips on either side of the aircraft for each 5-km transect segment were counted and recorded into tape recorders. Groups of more than 10 animals were also 
photographed and later counted with the aid of a $10 \times$ binocular microscope. Each 5-km transect segment was taken as an observation unit. Animal counts from the two observers on either side of the aircraft were summed and recorded on the basis of Universal Transverse Mercator (UTM) grids to the nearest $25-\mathrm{km}^{2}$ unit. Population estimates (PE) and standard errors (SE) were calculated using Jolly's Method 2 [41]. PE is estimated as $P E=N \bar{y}$ and its $\mathrm{SE}$ as $S E=\sqrt{\frac{N(N-n) S^{2}}{n}}$ where $\bar{y}$ is the sample mean, $S^{2}$ is the sample variance, $n$ is the sample size, and $N$ is the number of observations required to completely cover the study area.

The 11 ungulate species we considered include, in order of their peak abundance in the park, common wildebeest, plains zebra, impala Aepyceros melampus, Coke's hartebeest Alcelaphus busephalus, African buffalo Syncerus caffer, common eland, Thomson's Gazelle, common warthog Phacochoerus africanus, Grant's gazelle Nanger granti, giraffe Giraffa camelopardalis, and common waterbuck Kobus ellipsiprymnus.

\section{STATISTICAL ANALYSIS AND MODELLING}

We first tested for seasonality in numbers of each ungulate species within the national park by testing if the mean counts differed between blocks of two consecutive months, represented by a categorical variable with six levels, assuming a negative binomial error distribution and a log-link function to account for non-normality of counts, many zero counts, non-homogeneous variance and clustering of animals. We compared the least squares means across months using multiple pairwise comparisons, adjusted for multiplicity using simulation adjustment. The denominator degrees of freedom of Wald-F tests of the effect of month was adjusted for small sample size using the Kenward-Roger method [42], with autocorrelation and nonlinearity of counts accounted for using penalized B-spline [43] smoothing covariance structure. Temporal trends in the bi-monthly counts of the ungulate species showing no seasonal variation were modelled using a multivariate semiparametric generalized linear mixed model, assuming a negative binomial error distribution and a log-link function. This model allowed for a trend common to all species and trends specific to individual species. Trends were modelled using a penalized cubic B-spline smoothing covariance structure with equally spaced interior knots placed on the running time of surveys (February 1989, ..., June 2011) and a third-order difference penalty on the spline coefficients [44]. The model was fitted by restricted $\log$ pseudo-likelihood within a mixed model framework in the SAS GLIMMIX procedure [45, 46]. A similar model was used to model trends in the DRSRS total counts for the AthiKaputiei ecosystem, as well as trends shown by migratory wildebeest and zebra, considering the wet and dry season counts separately.

We related annual population changes to the separate effects of the annual, dry and wet season rainfall components and joint effect of the wet and dry season rainfall components in the preceding one to two years using the population growth rate $r=\ln \left(N_{t} / N_{t-1}\right)$ as the response variable in linear regression models, where $N_{t}$ is the average monthly population total from counts in calendar year $t$. For migratory wildebeest and zebra, similar analyses were not conducted because of wide seasonal fluctuations in numbers due to migratory movements. We did not consider density feedbacks in these models because sampling error can generate spurious indications of density dependence in population growth. Further analyses were undertaken replacing rainfall measures with the annual or seasonal mean NDVI indexing the amount of green vegetation produced in response to the rainfall. While rainfall records are location-specific, NDVI represents the lagged effects of rainfall and other influences on vegetation production over broader areas. We also related changes in the seasonal mean count totals $N_{t}$, indicating population shifts between the park and the adjoining plains, to the current wet and dry season rainfall and NDVI components, and changes in the annual mean count totals, indicating the prevailing population abundance level, to longer term influences on habitat conditions of annual and seasonal rainfall averaged over 4-6 year windows. The relationships considered in these regressions included non-linear responses to rainfall variation using a negative binomial regression with a log link function and the model described in [47]:

$\mu=\exp \left(a x+b x^{2}+c \ln (x)+d x \ln (x)\right)$

and its simplified forms:

$$
\begin{aligned}
& \mu=\exp \left(a x+b x^{2}\right), \\
& \mu=\exp (a x+c \ln (x)), \\
& \mu=\exp (c \ln (x)) \text { and } \\
& \mu=\exp (a x),
\end{aligned}
$$

where $\mu$ is the logarithm of the expected animal abundance and $x$ is rainfall.

We used model selection based on the corrected Akaike Information Criterion (AICc) to select the combination of rainfall and NDVI components and modeled relationship that was most consistent with the data [48].

\section{Relating Wildlife Density to Livestock Density and Ag- gregate Livestock Biomass}

We correlated trends in density of each wildlife species in all the $5 \times 5 \mathrm{~km}^{2}$ observation units to the corresponding densities of cattle, shoats (combined sheep and goats), and donkey and the combined livestock biomass density. We interpreted a negative correlation between wildlife and livestock density or biomass as indicating competition with or displacement by livestock.

\section{Mapping Changes in Spatial Distribution of Herbivore Density}

Since the DRSRS aerial counts are a very small sample of the total count area there is considerable variability in counts between years in each observation unit. Thus, we averaged the counts for each species in each counting unit over several years in each decade to reduce the variance and examine how herbivore density changed over time and space. 1) We summed up all the individuals of each species counted in each unit and divided the sum by the sampling 
fraction and area of each unit to obtain a density estimate for each species in each unit and survey combination. 2) We next calculated the average density of each species in each unit across all surveys conducted in each decade (1970s, 1980s, 1990s and 2000s). 3) We also calculated the average density of each species in each unit across all surveys. 4) For all units with a mean density across all surveys greater than zero, we further computed the $25^{\text {th }}, 50^{\text {th }}$ and $75^{\text {th }}$ percentiles of density for each species. We then recoded the density of each species in each unit in terms of the percentiles as follows. 5) If the overall mean density for a species in a given unit was zero then the mean density for the species in that unit was set to zero for all the decades. 6) If the mean density for a species in a unit in a given decade was greater than zero but less than or equal to the $25^{\text {th }}$ percentile of density for the unit over all surveys then the mean density for the unit was set to the $25^{\text {th }}$ percentile for the decade. 7) If the $25^{\text {th }}$ percentile of density for a given unit over all surveys was less than the mean density for the unit in a given decade but the decadal mean density was less than or equal to the median density for the unit over all surveys then the mean density for the decade was set to the median density for all surveys. 8) If the median density for a given unit over all surveys was less than the mean density for the unit in a given decade but the decadal mean density was less than or equal to the $75^{\text {th }}$ percentile of density for the unit over all surveys then the decadal mean density was set to the $75^{\text {th }}$ percentile of density for all surveys.

We plotted the recoded densities for each species in each observation unit against the UTM coordinates for the center of each unit and decade combination. We assigned a different colour to each of the four density categories in each decade $\left(0,25^{\text {th }}, 50^{\text {th }}\right.$ and $75^{\text {th }}$ percentiles $)$ and used the same colors for all the four decades to track how the density of each species changed in each unit between the decades. Using the same scale and colour schemes for the maps of all the four decades enabled us to directly compare the varying levels of density for the same species over time and identify where changes occurred and the type of change. A more detailed analysis of the influence of fences, settlements, roads and other landscape features on changes in wildlife and livestock population abundance and distribution in the Athi-Kaputiei ecosystem is undertaken in Said et al. [49].

\section{RESULTS}

\section{Trends in Rainfall, NDVI and Temperature}

The annual rainfall was extremely high in 1962 and 1998 , with very wet conditions also experienced in 1963, 1964, 2001 and 2003 (Fig. 1b-d). The exceptional flooding through 1997-98 was due to the strongest ENSO episode on instrumental record, reinforced by the Indian Ocean Dipole [50]. Extreme droughts were experienced in 1961, 1975-76, 1982, 1984, 1999-2000 and 2008-09, while rainfall remained persistently low through 1972-76 and 1993-97. Dry season rainfall was exceptionally low in 1968-70, 1986, 2004 and 2005, persistently high from 1972 through 1977, and also high in 1998, 2003 and 2007. During 2009 the Empakasi River and most dams became dry, apart from a few isolated pools (personal observations, JO Ogutu). During the droughts of 2005 and 2008-2009, huge herds of livestock escaping the drought in other parts of Kajiado County concentrated in the Athi-Kaputiei ecosystem and worsened the effect of this drought on wildlife and resident livestock in the ecosystem [51].

The NDVI did not consistently reflect the rainfall records. The wet season NDVI was very high during 1998 and 2001, and remained persistently high from 1990 through 1995 (Fig. 2a). It remained persistently low, except for one year, from 2002 through 2008. The dry season NDVI was unusually high in 2006, 2008 and 2009 (Fig. 2b). Based on contrasts of constructed penalized cubic spline effects [24, 46] placed on the running time at January 1961 and January 2013, the minimum monthly temperature increased by $1.81 \pm 0.46{ }^{\circ} \mathrm{C}\left(t=3.97, D F=1231, P=7.7 \times 10^{-5}\right)$ from $12.98 \pm 0.41{ }^{\circ} \mathrm{C}$ to $14.79 \pm 0.20{ }^{\circ} \mathrm{C}$ between January 1961 and January 2013 , while the maximum temperature increased by a mere $0.09 \pm 0.56{ }^{\circ} \mathrm{C}(t=0.16, D F=1231, P=0.874)$ from $25.3 \pm 0.41$ to $25.4 \pm 0.39{ }^{\circ} \mathrm{C}$ between January 1961 and January 2013. Fig. (A3).

\section{Seasonal Variation in Counts}

Only wildebeest $\left(F_{5,113.9}=4.405, P=0.0011\right)$ and zebra $\left(F_{5,117.9}=7.27, P=5.750 \times 10^{-6}\right)$ showed significant monthly variation in numbers counted in the park, indicating migratory influxes. Wildebeest concentrated within the park during the late dry season months spanning August-October. Very few wildebeest were found in the park during the wet season months, except for an influx in April 1992 and early arrival in June 2000. Zebra movements in and out of the park were erratic, with many animals remaining in the park during the wet season months in some years, notably in April 2000 and February 2006.

\section{Population Trends}

The total wildebeest population in the ecosystem fell from almost 30,000 animals counted in 1978 to around 16,000 between 1978 and 1986, and under 6,000 animals after 1997 (Fig. 3). Before 1982, the mean number of wildebeest counted in the park during the dry season fluctuated widely, with relatively few wildebeest recorded for several years after the severe drought of 1960-61, when many animals died (Fig. 4). After 1990, peak dry season numbers of wildebeest in the park declined from almost 10,000 towards 7,000 by 1997 (Fig. 5), representing most of wildebeest on the Athi-Kaputiei Plains. In 1998 following extremely high wet season rainfall, only 700 wildebeest entered the park, while merely 1500 appeared in the park in the following dry year. In 2000, a dry year, a seasonal influx amounting to over 5,000 wildebeest was recorded. In the following three wet years, fewer than 100 wildebeest appeared in the park in the dry season, and merely $160-250$ in following years, except in 2005 when a peak total of 590 was counted. Despite the severe drought conditions that prevailed in 2009, only a few hundred wildebeest entered the park. Statistical relationships between population growth and rainfall or NDVI (Table A1) reflected mainly the progressive decline in the wildebeest population. 


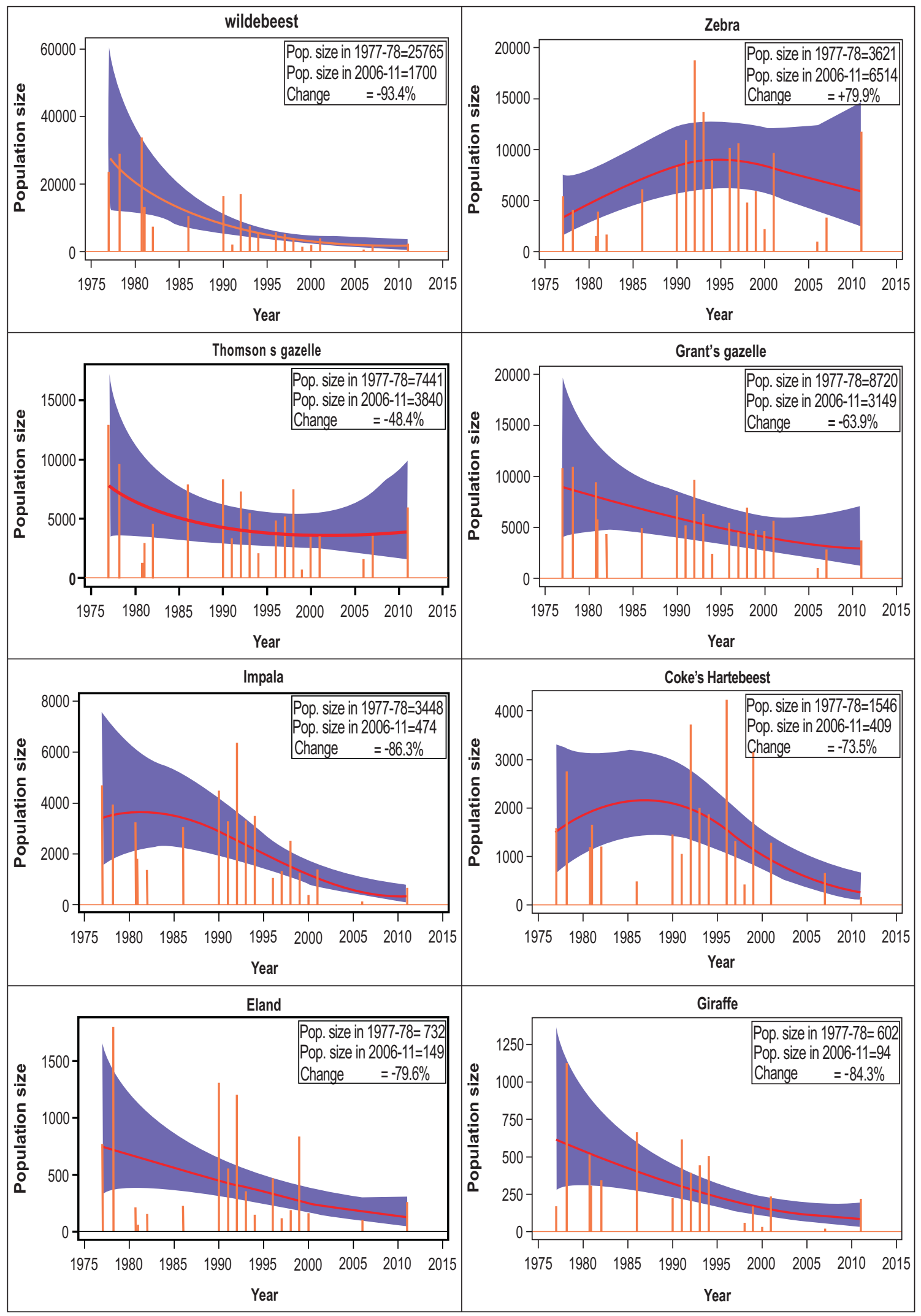

Fig. (3). Trends in estimated population sizes (vertical needles), for 8 of the 11 ungulate species (warthog, waterbuck and buffalo were rare in Athi-Kaputiei Plains) found in the Athi-Kaputiei Ecosystem during 1977-2011 based on aerial sample surveys conducted by the Department of Resource Surveys and Remote Sensing of Kenya (DRSRS). The solid lines are the estimated trend curves whereas the shaded bands are the $95 \%$ pointwise confidence bands. 


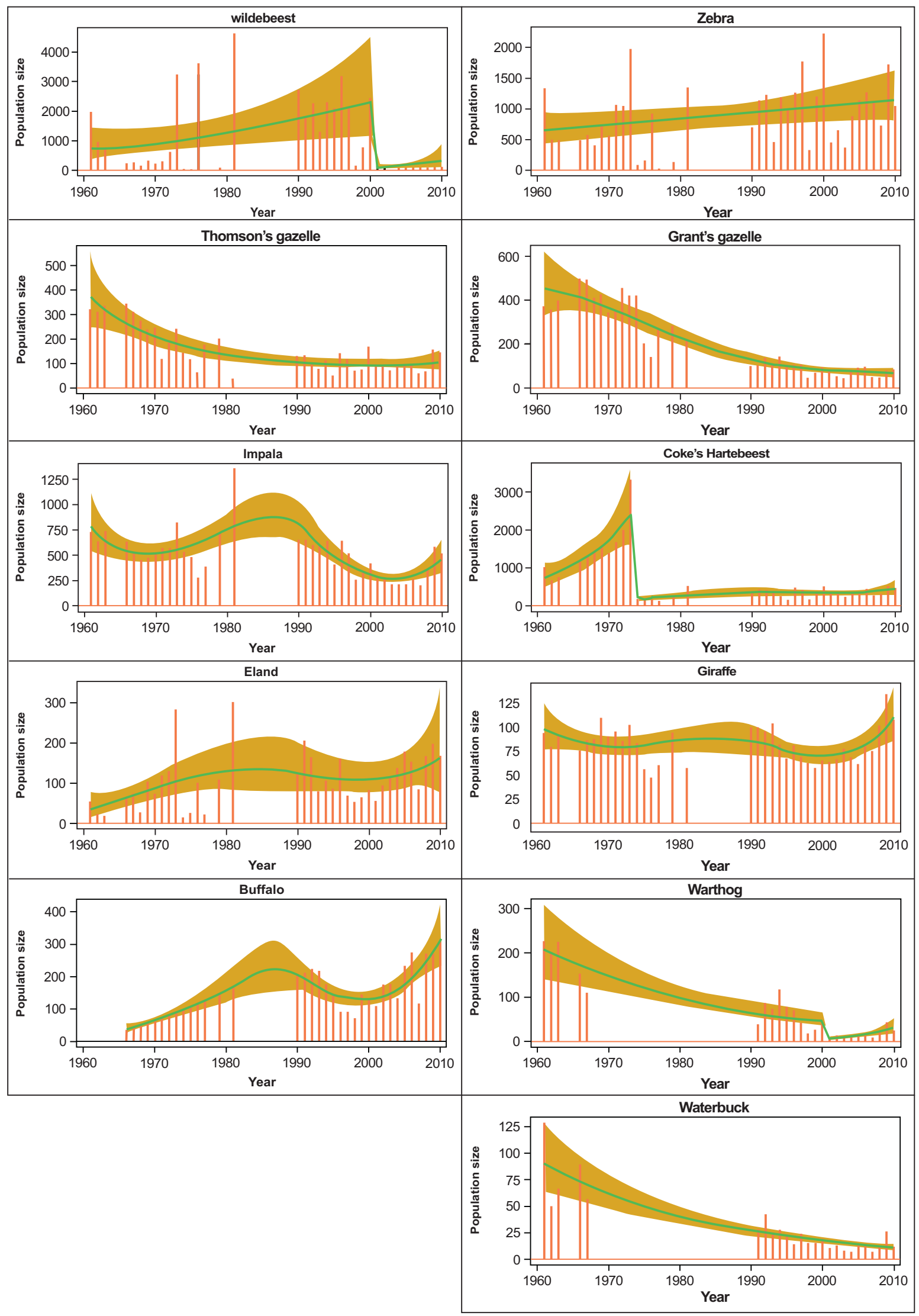

Fig. (4). Trends in annual averages of monthly (1961-81) and bimonthly (1989-2011) ground total counts of 11 ungulate species in Nairobi National Park. Vertical needles are the estimated population sizes, solid lines are the estimated trend curves and shaded bands are the $95 \%$ pointwise confidence bands. 

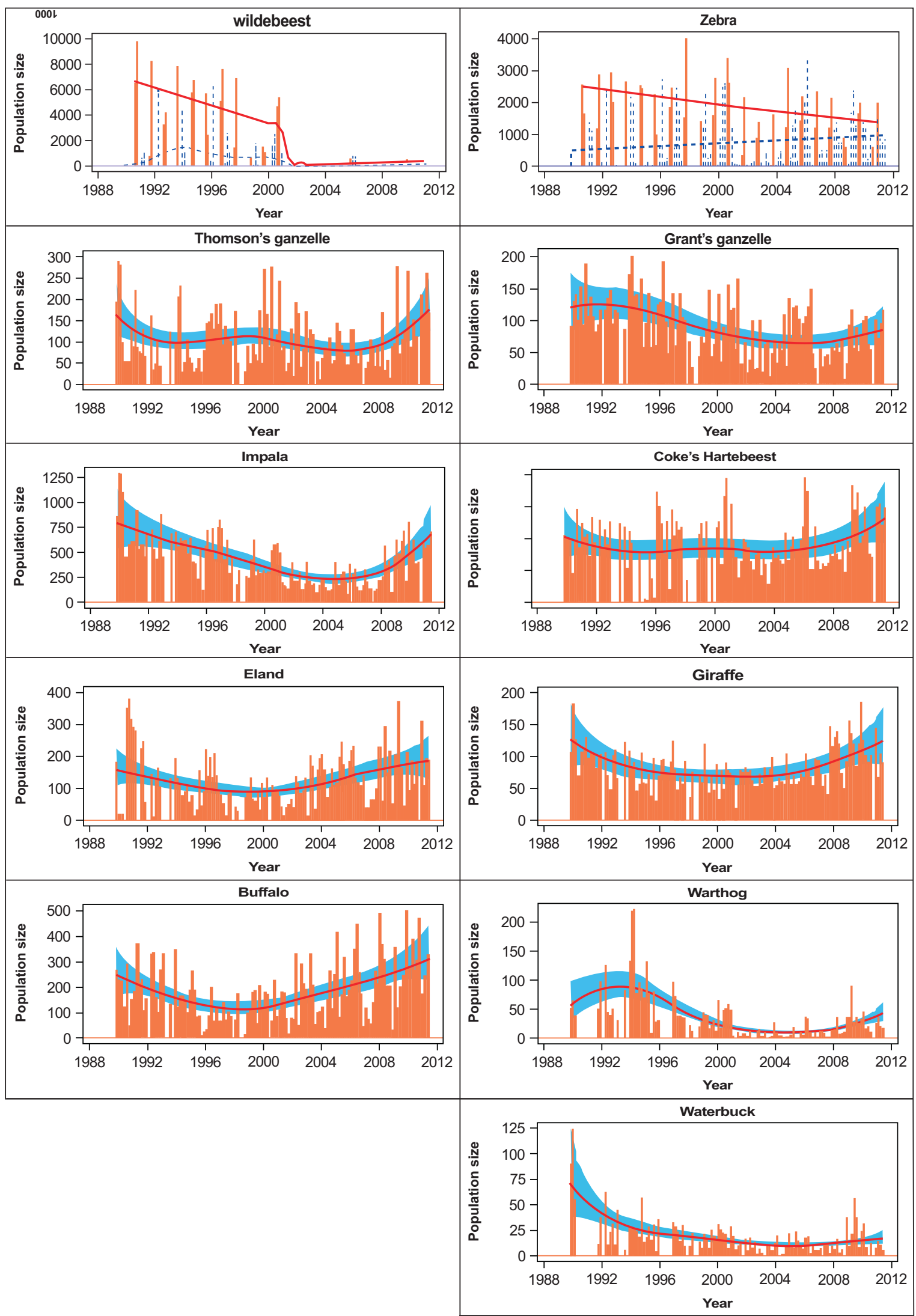

Fig. (5). Trends in bimonthly ground counts (vertical needles) of 11 ungulate species counted in Nairobi National Park during 1989-2011. Solid lines are the estimated trend lines whereas shaded bands are the $95 \%$ pointwise confidence bands. For zebra and wildebeest, solid needles without arrows and thick solid lines refer to the dry season whereas dotted needles with arrows and dotted lines to the wet season. 
Counts of zebra over the ecosystem indicated a regional total exceeding 10,000 (Fig. 3), including 1,000-2,000 on average within the park (Fig. 4). No regional or local trend in the zebra population was evident. From 1990 onwards, peak numbers of zebra counted within the park during the dry season amounted mostly to 2,000-3,000, with a maximum of over 4,000 recorded in October 1997 following two dry years (Fig. 5). Fewer than average numbers of zebra were counted within the park in 1998 when rainfall was extremely high, and during 2002-03 when preceding rainfall had also been very high.

Hartebeest numbers within the park crashed from over 3,000 animals prior to the 1972-1973 drought to 500-800 thereafter (Figs. $4 \& 5$ ), representing a small fraction of the Athi-Kaputiei ecosystem population of 2,000-4,000 (Fig. 3). The estimated impala population within the Athi-Kaputiei Plains prior to 1980 was 4,000-6,000 (Fig. 3), with 500-800 animals counted within the park (Fig. 4). After 1990, impala showed a downward trend in both the plains and the park, towards 400 or fewer animals in the park after 2002 (Figs. 3 \& 5). Numbers of both Thomson's and Grant's gazelles within the park were also a small fraction of their regional populations of 4,000-8,000 (Fig. 3). These gazelles showed lower total numbers in both the park and the plains after 1989 than they had attained prior to 1981 (Figs 3 \& 4).

Giraffe showed an overall decline in the plains region, from around 1,000 towards under 200 animals, but the park numbers remained static at around 100 (Figs 3-5). The regional eland population within the plains was around 1,000 animals, but eland numbers had declined dramatically by 2006-2011 (Fig. 3), while eland numbers counted within the park varied between 100 and 400 animals (Figs. 4 \& 5). Warthog numbers within the park crashed from a peak of over 200 counted in 1994 to under 30 after 2000. Waterbuck numbers within the park also declined from an early peak of over 100 towards no more than 10-25 animals. In sharp contrast, the buffalo total within the park expanded from a nucleus of 11 animals introduced in 1965 to over 300 by 1991 (Figs 4 \& 5). Thereafter buffalo numbers fell to a low of under 200 by 1997, before recovering towards a maximum count approaching 500. Buffalo were rarely seen elsewhere in the ecosystem during the aerial surveys.

\section{Regional Population Shifts}

Several of the ungulates moved between the park and the plains depending on variation in rainfall. Thus, wet season counts of hartebeest within the park were low in 1998 and other years with high rainfall. Higher than usual numbers of hartebeest were recorded in the park in the dry seasons of 1996 and 2000, following low wet season rainfall. Low numbers of impala were found within the park during 1998, and in 2003 when rainfall was also high. Relatively few gazelles were recorded within the park in 1998, and in the wet season of the following dry year. Thomson's gazelle numbers within the park also dropped in the wet season of 2007 following high early rains. Eland counts were very low in the wet season of 1998, but low numbers were also recorded in the dry season of 1993, following low wet season rainfall. The number of buffalo counted within the park increased sharply between 2001 and 2002, indicating movement of animals from the park to the plains due to the heavy rainfall in 2001 and back into the park following low rainfall, while low buffalo numbers were recorded in 2007 suggesting a temporary exodus in this wet year.

\section{Rainfall Influences}

Dry season numbers of buffalo, Thomson's gazelle, eland, hartebeest and zebra within the park were lower when the NDVI was higher in the preceding wet season, while Grant's gazelle, giraffe, warthog and waterbuck numbers showed a positive relationship to the wet season NDVI (Table A1, Fig. A5 in supplementary material A). For impala and wildebeest, numbers within the park in the dry season showed a humped (quadratic) relationship with the NDVI of the current wet season (Table A1, Fig. A5). Numbers of eland and waterbuck within the park during the dry season increased with increasing NDVI of the current dry season, while numbers of zebra, Thomson's and Grant's gazelles and hartebeest reduced as NDVI in this dry season increased (Table A1, Fig. A5). The numbers of wildebeest and impala in the dry season increased to a peak at intermediate levels of the current wet season NDVI, numbers of buffalo decreased whereas those of warthog increased with increasing current wet season NDVI (Table A1, Fig. A5). Wet season numbers of Thomson's gazelle, impala, warthog and waterbuck in the park were higher when NDVI in that wet season was higher, while a contrasting relationship was evident for zebra, hartebeest, eland and buffalo (Table A1, Fig. A5). Grant's gazelle and wildebeest numbers showed humped relationships whereas giraffe showed no relationship with NDVI in the current wet season. Relationships between population totals and both seasonal components of NDVI were stronger than those with both seasonal components of rainfall for all species (Table A1, Fig. A5).

Relationships between annual population change and rainfall were found for Grant's gazelle, giraffe, impala, warthog and waterbuck, but similar relationships with NDVI were stronger for buffalo, eland, impala and Thomson's gazelle only (Table A2 in Supplementary material A). However, differences between the influences of rainfall and NDVI were marginal for all the species, as revealed by the information theoretic model selection criteria for the selected best models. The best supported components of either rainfall or NDVI were positively correlated with annual population growth rate (Table A2). Prior wet season rainfall had a positive influence on the number of buffalo counted in the park, but count totals within the park were negatively associated with the preceding rainfall conditions for the remaining 10 ungulate species (Fig. 6, Table A3 in Supplementary material A).

Wildlife and livestock suffered heavy mortality during severe droughts. Accordingly, the aggregate wildlife and livestock biomass decreased strikingly in Athi-Kaputiei Ecosystem during the severe droughts of 1982, 1999-2000 and 2005-2006 (Fig. 7).

\section{Anthropogenic Influences}

Kenya Government Censuses conducted decadally since 1969 showed that human population in Kajiado County 


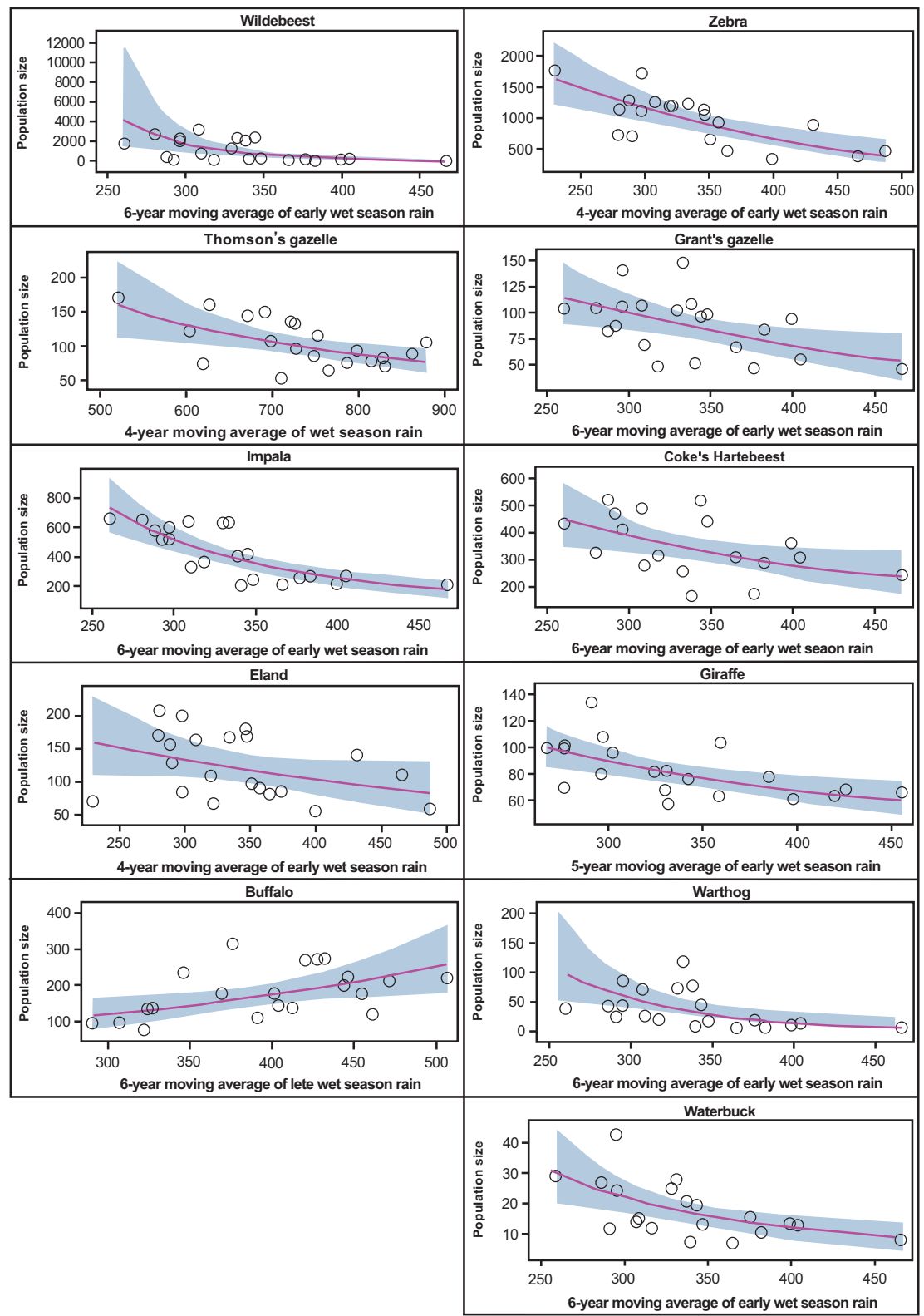

Fig. (6). Relationships between annual averages of ground counts and cumulative moving average rainfall components during $1990-2011$. The components shown are early wet (October-January), late wet (February-May), wet (October-May) and annual (October-September) components. Numeric suffixes in rainfall component names indicate the time window in years over which moving averages of the component were computed.

(22106 $\mathrm{km}^{2}$ ), incorporating the Athi-Kaputiei plains, grew from 85,903 in 1969 to 406,054 in 1999 and 687,312 by 2009. This trend was associated with a marked increase in the number of houses, fences and other developed features (Fig. A1 in Supplementary material A), a decline in the number of donkeys, sheep and goats but a more stable average number of cattle (Fig. A4 in Supplementary material A). Livestock, especially cattle, dominated the aggregate large herbivore biomass in the Athi-Kaputiei Plains throughout the 1977 to 2011 aerial monitoring period (Fig. 7). The contribution of livestock to the total herbivore biomass increased from an average of $69 \%$ during 1977-1980 to $89 \%$ during 2006-2011 (Fig. 7). This trend was associated with the replacement of wildebeest as the most dominant wild herbi- vore species in terms of biomass by zebra in 1991 (Fig. 7). However, there have been much more dramatic changes in the Athi-Kaputiei ecosystem that human populations, fences and livestock numbers alone cannot fully quantify, like industrial expansion, town build-up, expansion of old roads, construction of new roads and poaching, that degrade, fragment and truncate wildlife habitats [26, 28, 52,53]. These changes were not consistently monitored and quantified alongside the livestock and wildlife numbers, thus precluding a detailed spatial analysis of their influences on trends in herbivore numbers and distributions.

Nevertheless, the changes were concurrent with dramatic contractions in the spatial distributions of all the wildlife 


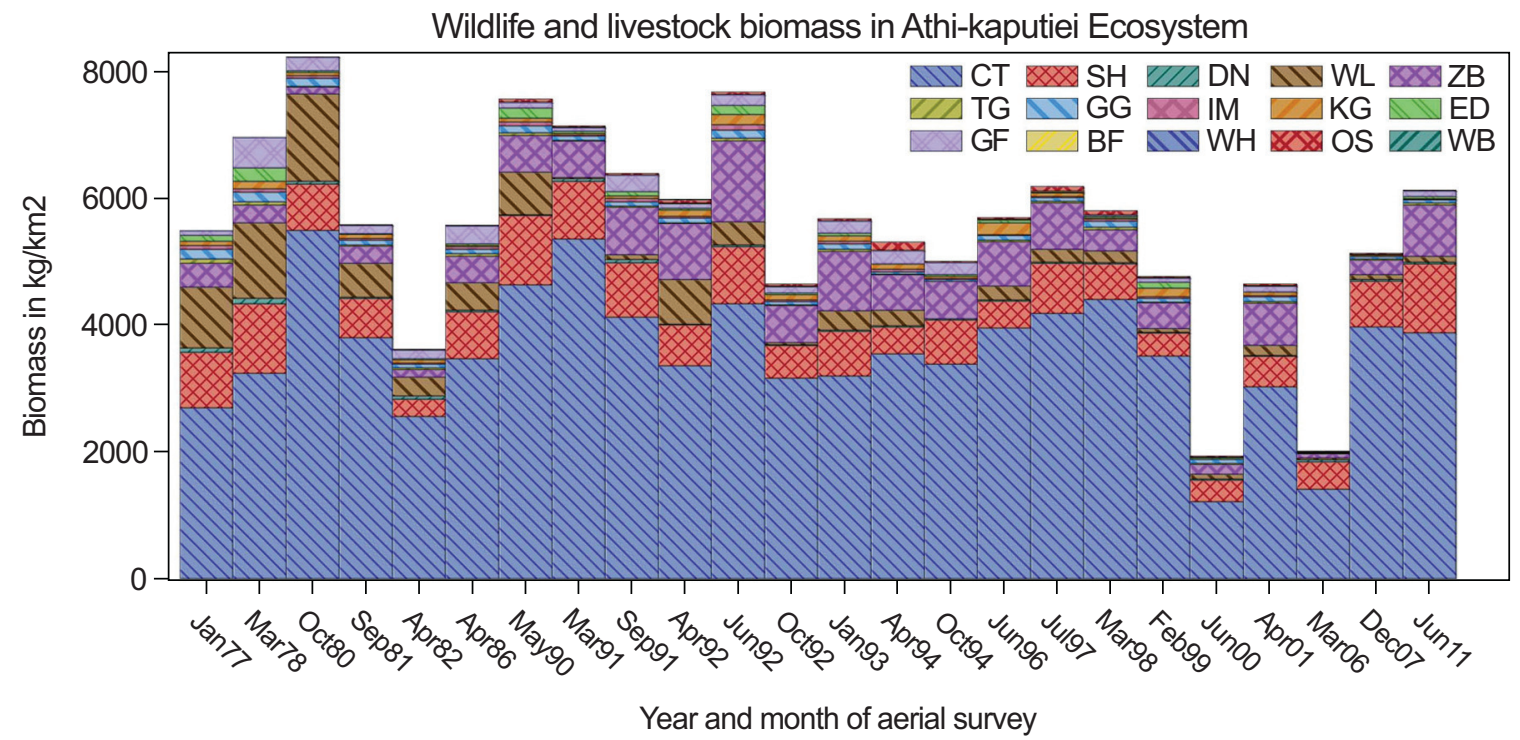

Fig. (7). Temporal trend in cumulative biomass of wildlife and livestock species occupying the Athi-Kaputiei Ecosystem during $1977-2011$. The unit weights (in kg) used to compute biomass are for wildebeest (WL, 120), zebra (ZB, 200), Thomson's gazelle (TG, 15), Grant's gazelle (GG, 40), impala (IM, 40), hartebeest (KG, 125), eland (ED, 350), giraffe (GF, 750), buffalo (BF, 450), warthog (WH, 45), waterbuck (WB, 160), ostrich (OS, 114), cattle (CT, 180), shoats (sheep and goats, SH, 18) and donkey (DN, 130), respectively.

species, most notably of wildebeest, giraffe and impala, between the 1970s and the 2000s. But the distribution of zebra surprisingly expanded in the same period (Fig. A6). The contraction in wildlife distribution was accompanied by expansion of livestock distribution to densely cover the entire ecosystem between the 1970s and 2000s (Fig. A6). This implies competition with and/ or displacement of wildlife by livestock. Over the course of the monitoring period most wildlife and livestock species were most widely distributed in the 1990s (Figs A6 in Supplementary Materials A). Further indirect evidence of competition with, or displacement by livestock, is provided by significant negative correlations between trends in wildlife and livestock densities in each $5 \times 5$ $\mathrm{km}^{2}$ observation unit over the 1977-2011 monitoring period (Table A6). Specifically, wildebeest, eland and buffalo densities were significantly lower where cattle density was high in the ecosystem. Similarly, wildebeest, eland, hartebeest and Thomson's gazelle densities were significantly depressed where the density of sheep and goats was high. Lastly, high donkey density was associated with low densities of wildebeest, zebra and Thomson's gazelles (Table A6). Results for ostrich (Struthio camelus) based on similar analyses to those for the ungulate species are summarized in Supplementary materials B.

\section{DISCUSSION}

Our expectation that the effect of land use changes within the plains on animal numbers within the park would be greatest for migratory ungulate species was supported in the case of wildebeest, but not zebra. Numbers of Thomson's gazelle found within the park did not vary seasonally, indicating that their local population was not migratory. The earlier migration of Grant's gazelles from the Athi-Kaputiei plains to the slopes of the Mau and the Ol Doinyo Sapuk
(Kilima Mbogo) Hills and the uplands between Ngong Hills and El Doinyo Narok Hills in the wet season when the plains became swampy and muddy, and to the uplands north of Nairobi (Ruiru-Thika) in the dry season [54, p. 126, 177], had long collapsed. The collapse followed major declines in gazelle numbers in Athi-Kaputiei and throughout most of Kajiado due to hunting and overgrazing by livestock resulting in bush encroachment, depletion of the plains grasses and semi-desert conditions [37, p. 233]. Eland numbers declined dramatically and their range had contracted critically in AthiKaputiei by 2006-2011 despite their wide roaming and migratory movements.

Relatively few wildebeest entered the park in the dry seasons of 1998 and 1999, following extremely high rainfall in the wet season of 1997-98, and the expected dry season influx did not occur even in 2009 despite severe drought conditions. The migration had essentially collapsed with regard to dependence on the park as a dry season refuge. In earlier times when they were still abundant, far more wildebeest and other wildlife species, livestock and pastoralists migrated seasonally from the Athi-Kaputiei Ecosystem to Ngong Hills, Nairobi, Ruiru-Thika and Ol Doinyo Sapuk Hills [26]. A count by the Game Department in 1948 found 15.5 wildebeest $\mathrm{km}^{-2}$ (1814 animals) in Nairobi Park in January and 111.4 wildebeest $\mathrm{km}^{-2}$ (13034 animals) in September during the migration. On the Athi-Kaputiei Plains, the same count found $44.0 \mathrm{~km}^{-2}$ (96800 animals) in January and $5.2 \mathrm{~km}^{-2}$ (11440 animals) in September [55, p. 253]. But wildebeest numbers had reduced precipitously by 1960 when the Game Department estimated an average of 5000-7000 only on the Athi-Kaputiei Plains [37, p. 229].

The range of the Athi-Kaputiei wildebeest extended historically over $100 \mathrm{~km}$ north to Muranga and $300 \mathrm{~km}$ east to the Tana River before settlements and fences fragmented the 
countryside north and east of Nairobi [56, p. 73]. The wildebeest population ranged over most of Kajiado County up to the 1960s before it was fragmented by habitat degradation through overgrazing and encroachment of thornbush. This virtually isolated the Athi-Kaputiei Plains wildebeest from their counterparts in southern Kajiado, which also effectively broke up into separate populations in Amboseli and Lake Natron [56, p. 73]. These developments led to extermination of populations of several wildlife species, including wild dogs (Lycaon pictus), black rhinos (Ceratoreium bicornis) and buffalo on the Athi-Kaputiei Plains. Buffalo and rhinos were later reintroduced into Nairobi Park whereas wild dogs have recently re-appeared in the ecosystem.

A much smaller fraction of the regional zebra population moved between the plains and the park, and their migratory movements persisted with little change. Zebra numbers were far fewer in the Athi-Kaputiei ecosystem and their migration to the park had drastically reduced compared to earlier times when they were very abundant all over the Athi-Kaputiei Plains [37, p. 261]. In the early 1900s, Percival thought that they were becoming too numerous [37, p. 261]. By 1948 a count of zebra in Nairobi Park by the Game Department found $10.4 \mathrm{~km}^{-2}$ in January and $235.6 \mathrm{~km}^{-2}$ in September during the migration. On the Athi-Kaputiei Plains, the same count found $32.4 \mathrm{~km}^{-2}$ in January and $0.65 \mathrm{~km}^{-2}$ in September 1948 [37, p. 261]. But by 1960s zebra numbers had drastically reduced. Average monthly count of zebra on the AthiKuputiei Plains in 1960 found a paltry 5000-7000 animals [37, p. 262].

Fewer hartebeest, impala and gazelles were found within the park in wet years, especially in 1998 following exceptionally high rainfall. These species generally favour quite short grass, except for Grant's gazelle, which is primarily a low-level browser [57]. Buffalo showed the opposite response to both immediate and prior rainfall, in accordance with the taller grass that they generally favour. Low rainfall conditions attracted more animals into the park, apart from buffalo. Being situated at the high end of the regional rainfall gradient, the Nairobi Park grasslands serve essentially as a dry season or drought refuge.

Among the non-migratory species, only giraffe showed a substantially greater decline outside the park than within it. Hartebeest numbers within the park failed to recover from their extreme population crash during the drought of 197374. This was probably partly due to the collapse of the migration of the Athi-Kaputiei hartebeest to the uplands north of Nairobi in the dry season [54, p. 126]. This drought typified the heavy mortality that hartebeest often incurs in droughts due to lung parasites that are innocuous when the host eats enough food but becomes virulent when the host is in poor condition [54, p. 145]. Similar mortality of hundreds of hartebeest was also recorded near Ol Doinyo Sapuk Hills in the drought of 1907-1908 [54, p. 145].

Warthog numbers within the park dropped substantially after 2000, although with some recovery in the most recent years. Impala and both gazelle species showed progressive declines towards half or less of their earlier abundances outside as well as within the park. The buffalo used to prefer the Ngong Hills in the Ngong Hills National Reserve [55, p. 361] before they were exterminated. The 11 buffalo intro- duced into the park in 1965 showed a progressive increase to become a major constituent of the grazer biomass. The increase in buffalo numbers following the eviction of Somali livestock from the park is very similar to the changes in wildlife species composition that occurred when Maasai livestock were evicted from Ngorongoro Crater in Tanzania in 1974 and their burning of those grasslands was prohibited [58].

The land use developments and poaching that have taken place in the Plains appear to have affected especially the migratory wildebeest population. Expansion and intensification of the land use developments was concurrent with the dramatic population declines and range contractions. The ongoing declines in numbers of the vast herds of wildlife that roamed the Athi-Kaputiei plains till at least the early 1900s $[59$, p. $5-6,13,80,333]$ began with the spread of settlements and agriculture on to the plains from around 1903 [54, p. 244]. The land use developments include the barriers to animal movements presented by fencing, settlements, roads, and harassment by people, vehicles, dogs and livestock [26, 53]. Community scouts, local residents and press reports also report much illegal killing of wild ungulates, particularly of wildebeest. Wildebeest herds are easily driven into fences by poachers and dogs [52]. These reports indicate that some wildebeest have moved eastwards to the Machakos ranches and adjoining areas since the 1997 drought (D. Nkedianye, personal communication). The total number of wildebeest counted annually in the Machakos ranches from 1991 to 1999 averaged $(1150.7 \pm 207.2)$ while in 2011 it was 2148 animals. Wildebeest are unwelcome to pastoralists because they transmit Malignant Catarrhal Fever to cattle [60].

Pastoralists seem to be more tolerant of zebra, perhaps because zebra do not transmit diseases to domestic cattle. Zebra manoeuvre their way around fences and disperse when chased, making it harder for poachers to kill them in large numbers [52]. Moreover, zebra meat is not favoured by many local people [52]. Zebra commonly persist outside protected areas elsewhere in Kenya, including the pastoral ranches of Laikipia District [61].

However, grazing conditions within the national park may also have become less favourable for most wild grazers following the extremely high rainfall received in 1997-98, exacerbated by subsequent lack of burning to remove the accumulated rank grass. The peak NDVI was very high in 2001, despite the lesser wet season rainfall in that year compared with 1998, suggesting a carryover effect. The dry season NDVI remained exceptionally low through the three years following 1998, perhaps making conditions in the park even less attractive to wildebeest at this time of the year. The Maasai Mara region of the Serengeti ecosystem, which draws concentrations of migrant wildebeest and zebra in the dry season, has similar rainfall to Nairobi Park, but there, regular fires contribute to a mosaic of tall grass interspersed with green regrowth [62]. Wildebeest and zebra are commonly attracted to dry season burns in the Kruger National Park and elsewhere in South Africa where mosaic burning has become a management practice [63]. Greater grass production may not be beneficial for most grazers in moist grasslands receiving over $800 \mathrm{~mm}$ rainfall on average [64]. Zebra and buffalo are more tolerant of taller grass than most 
other grazers [65]. Mixed feeders favouring low-level browse as well as short grass, such as impala and the two gazelle species, could also have been adversely affected by a shift in habitat conditions towards taller grass, also making low shrubs and forbs less accessible [65]. The influxes of cattle into the park during droughts [52] had no apparent competitive effect on the wild ungulate populations, suggesting that the amount of forage retained in Nairobi Park during these droughts was not limiting.

With the regional wildebeest population now so greatly reduced, there may be little pressure for the remaining wildebeest to move into the park to find sufficient dry season forage. The number of wildebeest entering the park in the dry season was also low after 1962, following drought conditions that had resulted in the death of many animals [32]. But their population recovered because there were then far fewer people, settlements, fences and other land developments in the plains than in recent decades.

The catastrophic range contractions and reductions in ungulate numbers currently underway in the Athi-Kaputiei ecosystem is extremely worrisome because it corroborates an alarming general pattern that has been documented for many species in the Maasai Mara region [13, 66], Lake Nakuru National Park [24], previously for this ecosystem [26] and most other protected and unprotected lands in Kenya [67, 68, 69], as well as in large parts of Tanzania [14, 70, 71]. Wildebeest are especially at risk when their seasonal migrations take them well beyond protected area boundaries $[10,72]$. They also commonly constitute a major fraction of the ungulate biomass, and serve as principal prey species for the lions (Panthera leo) and other large carnivores [73] that are prime draw cards for tourists.

Predation is unlikely to have played much role in the dramatic ungulate population declines because large carnivores are few in Nairobi Park and far fewer outside the park. A total-area census of lions within Nairobi National Park found 35 individuals, including cubs, in 2011. Large carnivores following their prey from Nairobi Park to the neighouring pastoral areas on the Athi-Kaputiei Plains in the wet season are often killed by landowners to avenge depredation of livestock, human injuries or deaths. Between 1998 and 2004, at least 87 lions were killed in the Athi-Kaputiei Ecosystem [74].

We think that the future of Nairobi National Park as a wildlife reserve and tourist attraction is in imminent and serious jeopardy because of its small size, barriers to animal movements to the north, east and west rigidified by fences, major roads and increasingly densely settled Athi-Kaputiei Plains to the south. The proposed construction of the Nairobi Southern by-pass road along the southern edge of the park would, if carried out, further restrict the herbivore movements and greatly amplify these threats. This would add to the severe impediments presented to wildebeest movements from triangle II to I in Kitengela (Fig. A1) and on into Nairobi Park by densification of fences and settlements and heavy traffic along the main Athi-River-Namanga Road. This would threaten even the resident ungulate species that also shift seasonally between the park and the plains in response to the variable grassland conditions, across the regional rainfall gradient. Widened annual variation in rainfall as a consequence of global warming lurks as a compounding threat.

Initiatives have been launched to provide local residents with incentives to support conservation of open land for movement of wildlife (and livestock). One program attempts to better protect carnivores through payment of consolation fees for livestock losses to predators in the Athi-Kaputiei ecosystem (Table A4 in Supplementary material A). Another program provides pastoral landowners with payments ( $c a$. $\$ 3.75 /$ acre in 2005) to refrain from and report poaching by others and avoid fencing or subdividing their land into smaller parcels (Table A5 in Supplementary material A; [26, $52,53]$ to enable wild ungulates and their associated predators to continue to use the Plains as a dispersal area. In addition, local residents and the former Kajiado county council recently completed Kenya's first ever land-use plan for a pastoral area that, if implemented, could slow the pace of land sales and subdivision that is rapidly fragmenting this landscape (David Nkedianye, personal communication). Conservation of the remaining wildlife in the area will require that this new plan be implemented quickly and effectively. Negotiated conservation land purchases and easements would also promote conservation of wildlife. In addition, anti-poaching efforts should be strongly expanded, since the level of poaching, though largely unknown, must be high as evidenced by major losses of wildlife to the bushmeat markets $[27,75]$.

The success of these and other measures is partly dependent on how suitable conditions remain for wildebeest and other species within Nairobi Park. Because the park is located towards the high end of the rainfall gradient, conditions there favour tall, rank grass that is predominantly of low nutritional value for most wild ungulates [76], especially in years with elevated rainfall. Under these conditions, fire is an essential tool to remove moribund material and make new grass growth accessible during the dry season [63]. An effective fire management policy would entail burning sections according to a planned schedule, dependent on the prevailing rainfall conditions, as is done in the Kruger National Park and other protected areas in South Africa [63, 77]. This would likely retain areas offering green regrowth in the dry season for species favouring short grass, like wildebeest, especially during high rainfall years, as well as improving the nutritional value of the grassland as a forage buffer for all grazers during drought years. Promoting local heterogeneity in grassland conditions in this way could encourage the migratory wildebeest population to spend more time within the relative safety of the park, ameliorating the risks that they incur when they disperse through the plains. However, rapid, unplanned and unregulated expansion of the Nairobi Metropolis into Athi-Kaputiei ecosystem poses the greatest challenge yet to continued wildlife migration between Nairobi Park and the wider ecosystem.

In conclusion, the future of Nairobi National Park as a protected area for wildlife depends on management responses within the park as well as on actions to reduce the threats posed by poaching, expansion of industrial areas and towns, and other land use developments within the adjoining Athi-Kaputiei Plains. These actions should be directed towards counteracting the loss of wildlife itself as well as sus- 
taining and enhancing both local and regional heterogeneity in the habitat conditions that these large herbivores require to cope with the widened temporal variability in rainfall expected as a consequence of global warming. Urgent and decisive remedial actions are necessary to counteract adverse impacts on wildlife populations of the rapid and widespread changes currently underway in the Athi-Kaputiei ecosystem.

\section{CONFLICT OF INTEREST}

The authors confirm that this article content has no conflicts of interest.

\section{ACKNOWLEDGEMENTS}

We thank the Kenya Wildlife Service (KWS) and the Department of Resource Surveys and Remote Sensing of Kenya for permission to use the animal counts. Several KWS scientists assisted with making available the files containing the animal counts, especially Richard Bagine, Bernard Ngoru, Erastus Kanga and Lekishon Kenana. KWS and Friends of Nairobi National Park coordinated and also participated in conducting the bimonthly censuses. The Kenya Meteorological Department provided rainfall and temperature data. We thank Inge Buchard, David Nkedianye, Ogeli Makui and Nickson Parmisia for sharing their insights on changes in Nairobi Park and Athi-Kaputiei Plains. We are grateful to the editor and an anonymous reviewer for suggestions that helped improve an earlier version of this paper. The Belgian Government (DGIC BEL011) and USAID funded mapping of fences and other features in AthiKaputiei Plains through grants to the International Livestock Research Institute (ILRI) and the African Wildlife Foundation. The National Science Foundation of America (NSF) supported data processing, analysis and writing through Grants (Nos: BCS 0709671 and DEB-0342820) to ILRI. The Alexander von Humboldt Foundation (AvH) supported JO through a research fellowship at the Bioinformatics Unit, University of Hohenheim, Stuttgart, Germany. ESPA supported MS and SK through the project: Biodiversity, Ecosystem Services, Social Sustainability and Tipping Points in African Drylands (BEST, Gant No: NE/I0036731).

\section{REFERENCES}

[1] Craigie ID, Baillie JEM, Balmford A, et al. Large mammal population declines in Africa protected areas. Biol Conserv 2010; 143: 2221-8.

[2] Scholte P. Towards understanding large mammal population declines in Africa's protected areas: A west-central African perspective. Trop Conserv Sci 2011; 1: 1-11.

[3] Neumann R. Ways of seeing Africa: Colonial recasting of African society and landscape in Serengeti National Park. Ecumene 1995; 2:149-69.

[4] Homewood K, Trench PC, Kristjanson P. Staying Maasai? Livelihoods, Conservation and Development in East African Rangelands. New York: Springer 2009.

[5] Ogutu JO, Piepho H-P, Dublin HT, Bhola N, Reid RS. Dynamics of Mara-Serengeti ungulates in relation to land use changes. J Zool 2009; 278: 1-14.

[6] Newmark WD. Isolation of African protected areas. Front Ecol Environ 2008; 6: 321-8.

[7] Thuiller W, Olivier B, Hughes G, Alkemade JRM, Midgley GF, Corsi F. Vulnerability of African mammals to anthropogenic climate change under conservative land transformation assumptions. Glob Change Biol 2006; 12: 424-40.
IPCC. Climate change 2007. The physical science basis. Contribution of Working Group I to the Fourth Assessment Report of the Intergovernmental Panel on Climate Change, Solomon S, Qin D, Manning M, Chen Z, Marquis M, Averyt KB, Tignor M, Miller HL. Cambridge: Cambridge University Press 2007; 996.

[9] Owen-Smith N, Mills MGL. Manifold interactive influences on the population dynamics of a multispecies ungulate assemblage. Ecol Monogr 2006; 76: 73-92.

[10] Harris G, Thirgood S, Hopcraft JGC, Cromsigt JPGM, Berger J. Global decline in aggregated migrations of large terrestrial mammals. Endanger Species Res 2009; 7: 55-76.

[11] Spinage CA, Malthare JM. Is the Kalahari cornucopia fact or fiction? J Appl Ecol 1992; 29: 605-10.

[12] Berry HH. The wildebeest problem in the Etosha National Park: a synthesis. Madoqua 1997; 13: 151-7.

[13] Ogutu JO, Owen-Smith N, Piepho H-P, Said MY. Continuing wildlife population declines and range contraction in the Mara region of Kenya during 1977-2009. J Zool 2011; 285: 99-104.

[14] Msoffe FU, Kifugo SK, Said MY, et al. Drivers and impacts of land-use change in the Maasai Steppe of northern Tanzania: an ecological-social-political analysis. Land Use Sci 2011; 64: 261-81.

[15] Maddock L. The "migration" and grazing succession. In: Sinclair ARE, Norton-Griffiths M, Ed. Serengeti: dynamics of an ecosystem. Chicago; University of Chicago Press 1979, pp. 104-29.

[16] Fryxell JM, Wilmshurst JF, Sinclair ARE, Haydon DT, Holt RD, Abrams PA. Landscape scale, heterogeneity, and the viability of Serengeti grazers. Ecol Lett 2005; 8: 328-35.

[17] Hillman JC. Home range and movement of the common eland (Taurotragus oryx Pallas 1766) in Kenya. Afr J Ecol 1988; 26: 135-48.

[18] Deshmukh IK. A common relationship between precipitation and grassland peak biomass for east and southern Africa. Afr J Ecol 1984; 22:181-6.

[19] Boutton TW, Tieszen LL, Imbamba SK. Seasonal changes in the nutrient of East African grassland vegetation. Afr J Ecol 1988; 26:103-15.

[20] Tyson PD, Gatebe CK. The atmosphere, aerosols, trace gases and biogeochemical change in southern Africa: a regional integration. S Afr J Sci 2001; 97: 106-18.

[21] Nicholson SE, Kim, J. The relationship of the El Niño-southern oscillation to African rainfall. Int J Climatol 1997; 17: 117-35.

[22] Mills MGL, Biggs HC, Whyte IJ. The relationship between rainfall, lion predation and population trends in African herbivores. S Afr J Wild Res 1995; 22: 75-88.

[23] Ogutu JO, Owen-Smith N. Oscillations in large mammal populations: are they related to predation or rainfall? Afr J Ecol 2005; 43: 332-9.

[24] Ogutu JO, Owen-Smith N, Piepho H-P, Kuloba B, Edebe J. Dynamics of ungulates in relation to climatic and land use changes in an insularized African savanna ecosystem. Biodivers Conserv 2012; 21:1033-53.

[25] Ogutu JO, Owen-Smith N. ENSO, rainfall and temperature influences on extreme population declines among African savanna ungulates. Ecol Lett 2003; 6: 412-9.

[26] Reid RS, Gichohi H, Said MY, et al. Fragmentation of a peri-urban savanna, Athi-Kaputiei Plains, Kenya. In: Galvin KA, Reid RS, Behnke RH, Hobbs NT, Eds., Fragmentation in arid and semi-arid landscapes: Consequences for humans and natural systems. Dordrecht: Springer 2008; pp: 195-224.

[27] Barnett R. Food for Thought: the Utilization of Wild Meat in Eastern and Southern Africa. TRAFFIC East/Southern Africa, Nairobi, Kenya 2000; pp. 212

[28] Kimani K, Pickard J. Recent trends and implications of group ranch sub-division and fragmentation in Kajiado district of Kenya. Geogr J 1998; 164: 202-13.

[29] Imbahale SS, Githaiga JM, Chira RM, Said MY. Resource utilization by large migratory herbivores of the Athi-Kapiti ecosystem. Afr J Ecol 2008; 46: 43-51.

[30] Gichohi H. Functional relationships between parks and agricultural areas in East Africa: the case of Nairobi National Park. In: Prins HHT, Grootenhuis JG, Dolan TT, Ed. Wildlife conservation by sustainable use. Dordrecht: Kluwer, 2000; pp. 141-69.

[31] Foster JB, Kearney D. Nairobi National Park game census, 1966. E Afr Wildl J 1967; 5: 112-20.

[32] Foster JB, Coe MJ. The biomass of game animals in Nairobi National Park, 1960-66. J Zool 1968; 155: 413-25. 
[33] Foster JB, McLaughlin R. Nairobi National Park game census, 1967. E Afr Wildl J 1968; 6: 152-4.

[34] McLaughlin RT. Nairobi National Park game census, 1968. E Afr Wildl J 1970;

[35] EcoSystems Ltd. Amboseli/Lower Rift Regional Study. Final Report to the Wildlife Planning Unit, Ministry of Tourism and Wildlife, Nairobi, Kenya 1982.

[36] Norton-Griffiths M .Wildlife Numbers in Nairobi National Park, 1961-2002. Unpublished Report 2003.

[37] Simon N. Between the sunlight and the Thunder: The Wild Life of Kenya. London: Collins 1962

[38] Gichohi HW. The Ecology of a Truncated Ecosystem. The AthiKapiti Plains. Ph.D. Thesis. Leicester: University of Leicester 1996.

[39] Gichohi H. The effects of fire and grazing on grasslands of Nairobi National Park. MSc. Thesis. Nairobi: University of Nairobi 1990

[40] Norton-Griffiths M. Counting Animals. Nairobi: Africa Wildlife Leadership Foundation 1978.

[41] Jolly GM. Sampling methods for aerial census of wildlife populations. East Afr Agric For J 1969; 34: 46-9.

[42] Kenward MG, Roger JH. Small sample inference for fixed effects from restricted Maximum Likelihood. Biometrics 1997; 53: 98397.

[43] de Boor C. A Practical Guide to Splines. Revised ed, New York: Springer 2001.

[44] Eilers PHC, Marx BD. Flexible Smoothing with B-splines and Penalties. Stat Sci 1996; 11: 89-121.

[45] Ruppert D, Wand MP, Carroll RJ. Semiparametric regression. Cambridge: Cambridge University Press 2003.

[46] SAS Institute. SAS system for windows, Version 9.3. Carey, NC, USA: SAS Institute 2013

[47] Ogutu JO, Piepho H-P, Dublin HT, Bhola N, Reid RS. Rainfall influences on ungulate population abundance in the Mara-Serengeti ecosystem. J Anim Ecol 2008; 77: 814-29.

[48] Burnham KP, Anderson DR. Model Selection and multi-model inference: A practical information-theoretic approach. $2^{\text {nd }}$ ed. New York: Springer 2002.

[49] Said MY, Ogutu JO, Kifugo SC, et al. Land fragmentation in the Athi-Kaputiei Plains of Kenya through fencing: implications for wildlife conservation and pastoralism. Biodiveristy and Conservation. [Submitted].

[50] Webster PJ, Moore AM, Loschnigg JP, Leben RR. Coupled oceanatmosphere dynamics in the Indian Ocean during 1997-1998. Nature 1999; 401: 356-60.

[51] Nkedianye D, Ogutu JO, Said MY, Herrero M, Kifugo SC, Van Gardingen P. Mobility and livestock mortality in communally used pastoral areas: the impact of the 2005-2006 drought on livestock mortality in Maasailand. Pastoralism: 2011; pp. 1:17.

[52] Nkedianye D. Testing the attitudinal impact of a conservation tool outside a protected area: the case for the Kitengela Wildlife Conservation Lease Programme for Nairobi National Park. MSc thesis. Nairobi: University of Nairobi 2004.

[53] Nkedianye D, Radney M, Kristjanson P, Herrero M. Assessing returns to land and changing livelihood strategies in Kitengela. In: Homewood K, Trench PC, Kristjanson P Ed. Staying Maasai? Livelihoods, Conservation and Development in East African Rangelands. London: Springer 2009; pp. 115-49.

[54] Percival AB. A game ranger on Safari. London: Nisbet and Co. 1928.

[55] Sidney J. The past and present distribution of some African ungulates. Trans Zool Soc Lond 1965; 30: 1-396.

[56] Estes RD, East R. Status of the wildebeest (Connochaetes taurinus) in the wild 1967-2005 working paper no. 37 July 2009. WCS Working Papers: ISSN 1530-4426. Online posting: ISSN 15347389.

[57] Sinclair ARE. Does interspecific competition or predation shape the African ungulate community? J Anim Ecol 1985; 54: 899-918.
[58] Runyoro VA, Hofer H, Chausi EB, Moehlman PD. Long-term trends in the herbivore populations of the Ngorongoro Crater, Tanzania. In: Sinclair ARE, Arcese P, Eds. Serengeti II: dynamics, management and conservation of an ecosystem. Chicago: University of Chicago Press 1995; pp. 146-68.

[59] Meinertzhagen R. Kenya Diary (1902-1906). Edinbugh: Oliver and Boyd 1957.

[60] Bedelian C, Nkedianye D, Herrero M. Maasai perception of the impact and incidence of malignant catarrhal fever MCF) in southern Kenya. Prev Vet Med 2007; 78: 296-316.

[61] Georgiadis NJ, Olwero JGN, Ojwang GG, Romañach SS. Savanna herbivore population dynamics in a livestock-dominated landscape: I. dependence on land use, rainfall, density and time. Biol Conserv 2007; 137: 461-72.

[62] Dublin HT. Vegetation dynamics in the Mara- Serengeti ecosystem: the role of elephants, fire and other factors. In: Sinclair ARE, Arcese P, Eds. Serengeti II: dynamics, management and conservation of an ecosystem. Chicago: University of Chicago Press 1995; pp. 71-90.

[63] van Wilgen BW, Govender N, Biggs HC, Ntsala D, Funda XN Response of savanna fire regimes to changing fire-management policies in a large African national park. Conserv Biol 2004; 18 : $1533-40$

[64] McNaughton SJ, Georgiadis N. Ecology of African grazing and browsing mammals. Ann Rev Ecol Syst 1986: 17: 39-65.

[65] McNaughton SJ. Ecology of a grazing ecosystem: The Serengeti. Ecol Monogr 1985; 55: 259-94.

[66] Bhola N, Ogutu JO, Piepho H-P, et al. Comparative changes in density and demography of large herbivores in the Maasai Mara Reserve and its surrounding human-dominated pastoral ranches in Kenya. Biodivers Conserv 2012; 21: 1509-30.

[67] Norton-Griffiths M. Wildlife losses in Kenya: an analysis of conservation policy. Nat Res Modell 2000; 13: 1-16.

[68] Norton-Griffiths M. How many wildebeest do you need? World Econ 2007; 8: 41-64.

[69] Western D, Russell S, Cuthill I. The status of wildlife in protected areas compared to non-protected areas of Kenya. PloS ONE 2009; 4: 1-6.

[70] Stoner C, Caro T, Mduma SAR, Mlingwa C, Sabuni G, Borner M. Assessment of effectiveness of protection strategies in Tanzania based on a decade of survey data for large herbivores. Conserv Biol 2007; 21: 635-46.

[71] Caro T. Decline of large mammals in the Katavi-Rukwa ecosystem of western Tanzania. Afr Zool 2008; 43: 99-116.

[72] Bolger DT, Newmark WD, Morrison TA, Doak DF. The need for integrative approaches to understand and conserve migratory ungulates. Ecol Lett 2008; 11: 63-77.

[73] Scheel D, Packer C. Variation in predation by lions: tracking a moveable feast. In: Sinclair ARE, Arcese P, Eds. Serengeti II: dynamics, management and conservation of an ecosystem. Chicago: University of Chicago Press 1995; pp. 299-314.

[74] Frank L, Maclennan SD, Hazzah L, Bonham R, Hill T. Lion killing in the Amboseli-Tsavo ecosystem, 2001-2006, and its implications for Kenya's lion population. Nairobi: Kilimanjaro Lion Conservation Project and the Predator Compensation Fund and Maasailand Preservation Trust, 2006 [cited 20013 June 13];. Available from: http://www.johnbanovich.com/clients/banovichpride/PDF/LionKill ing506.pdf.

[75] Wato YA, Wahungu GM, Okello MM. Correlates of wildlife snaring patterns in Tsavo West National Park, Kenya. Biol Conserv 2006; 132: 500-9.

[76] Van Soest PJ. Nutritional ecology of the ruminant. Corvallis, Oregon, USA: O and B Books 1982

[77] Brockett BH, Biggs HC, van Wilgen BW. A patch mosaic burning system for conservation areas in southern African savannas. Int J Wildl Fire 2001; 10: 169-83.

\footnotetext{
Received: June 26, 2013

Revised: July 08, 2013

Accepted: July 11, 2013

(C) Ogutu et al.; Licensee Bentham Open.

This is an open access article licensed under the terms of the Creative Commons Attribution Non-Commercial License (http://creativecommons.org/licenses/by-nc/3.0/) which permits unrestricted, non-commercial use, distribution and reproduction in any medium, provided the work is properly cited.
} 